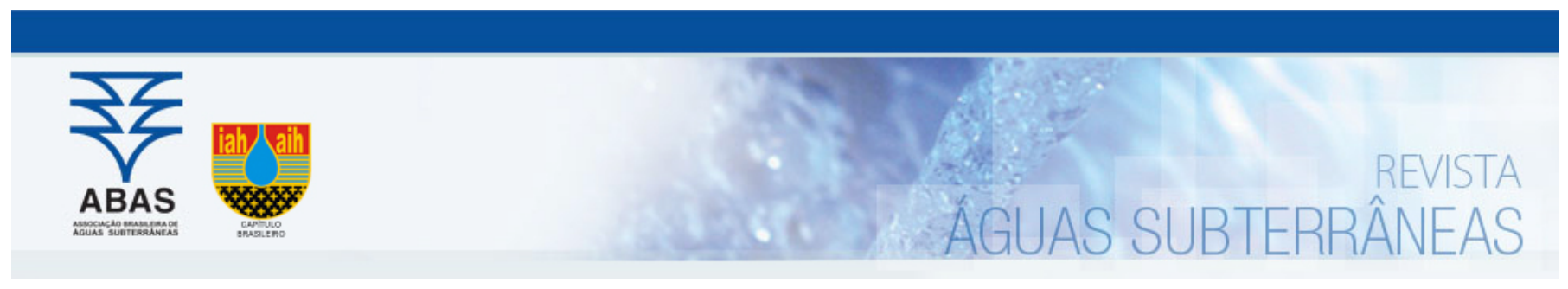

Estudos de Caso e Notas Técnicas

\title{
Determinação de ânions para análise da qualidade da água subterrânea no município de Medianeira (PR)
}

\section{Determination of anions for analysis of groundwater quality in the Medianeira city (PR)}

\author{
Éder Lisandro de Moraes Flores ${ }^{1}$; Rafael Flores de Campos $^{1}$; Cristiane Witcel1; Eduardo Eyng ${ }^{1}$; Alex Sanches Torquato ${ }^{1}$; Cristiane \\ Canan';
}

1Universidade Tecnológica Federal do Paraná, Campus Medianeira, Medianeira, PR, Brasil.

$\bowtie$ eder@utfpr.edu.br; rafaelcampos_@hotmail.com; cristiane_eng.ambiental@hotmail.com; eduardoeyng@utfpr.edu.br; alexstorquato@utfpr.edu.br; canan@utfpr.edu.br

\begin{tabular}{|c|c|}
\hline & Resumo \\
\hline $\begin{array}{l}\text { Palavras-chave: } \\
\text { Águas subterrâneas. } \\
\text { Ânions. } \\
\text { Qualidade das águas. } \\
\text { Aquífero Serra Geral. }\end{array}$ & 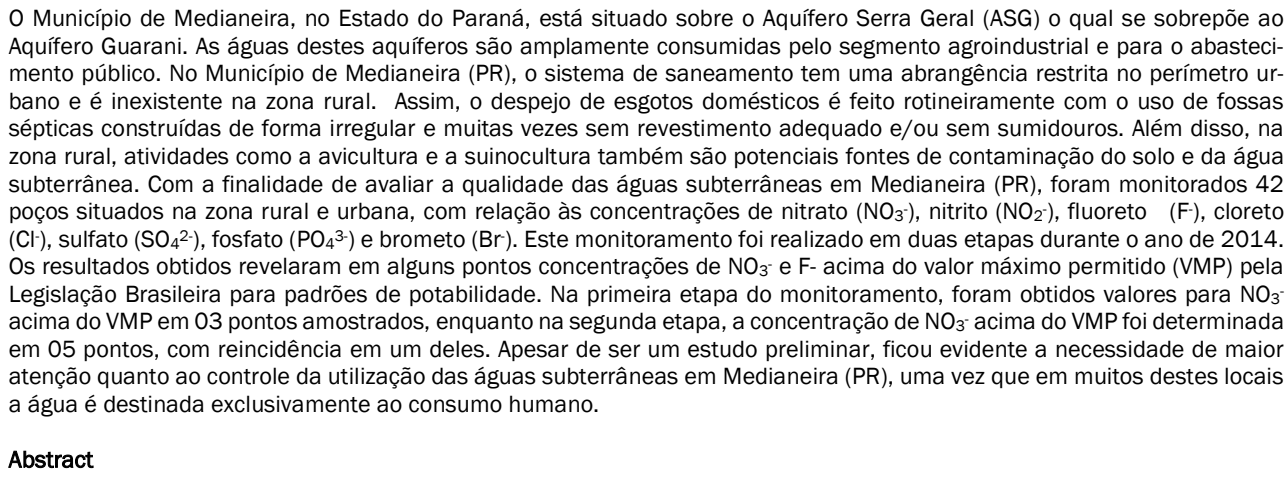 \\
\hline
\end{tabular}

DOI: http://dx.doi.org/10.14295/ras.v31i4.28863

\section{INTRODUÇÃO}

O uso de águas subterrâneas para consumo humano e atividades agroindustriais no Estado do Paraná tem se intensificado nos últimos anos devido principalmente à escassez da oferta de águas superficiais com boa qualidade e devido ao fácil acesso aos aquíferos que ocorrem na região, com destaque para o Aquífero Serra Geral, na Região Oeste do Paraná (ROSA FILHO et al., 2010). Embora as águas provenientes de fontes subterrâneas sejam, geralmente, de boa qualidade devido ao processo de filtração natural, elas também apresentam riscos de estarem poluídas de forma extensiva por águas residuárias e dejetos de origem humana ou animal (TUCCI \& CABRAL, 2003).

As fontes de contaminação em águas subterrâneas são, em muitos casos, diretamente associadas a diversas atividades antropogênicas. Na Região Oeste do Paraná, devido à forte vocação regional para a agroindústria, empreeendimentos voltados 
para a avicultura e suinocultura estão presentes em praticamente todos os Municípios (MEINERZ et. al., 2011). No Município de Medianeira (PR), o sistema de saneamento de esgotos está instalado em uma pequena fração do perímetro urbano. Assim, nas residências e condomínios, o despejo de esgotos domésticos é feito pelo uso de fossas sépticas. Entretanto, essas fossas são construídas de forma arcaica e irregular, muitas vezes sem revestimento adequando e sem a instalação de um sumidouro.

O nitrogênio é um composto de grande importância para o crescimento das plantas, porém, em determinadas condições, é convertido em nitrato, o qual pode ser absorvido pelas plantas ou lixiviado para a água subterrânea após a ocorrência de chuva pesada ou irrigação intensa (RICO-GARCíA et al, 2009). A mobilidade do nitrato em solo está relacionada a fatores como a textura e umidade do solo e à sua disponibilidade, sendo assim, o nitrato se torna a principal forma de nitrogênio associada à contaminação dos reservatórios de água subterrânea devido a atividades antropogênicas (SILVA et al. 2015).

Há um consenso claro em alguns estudos de que o consumo de águas contaminadas por atividades antropogênicas pode afetar a saúde humana. Dentre estes problemas, os casos de ocorrência de metahemoglobinemia em crianças são relatados como resultados da ingestão excessiva de nitrato $\left(\mathrm{NO}_{3}^{-}\right)$presente em águas (FERNICOLA \& AZEVEDO, 1981; MACILWAIN, 1995; KNOBELOCH et al., 2000; BRENDER et al., 2013).

A organização mundial da saúde (WHO, do Inglês, World Health Organization) estabelece o limite de $50,0 \mathrm{mg} \mathrm{L}^{-1}$ para $\mathrm{NO}_{3}^{-}$em águas destinadas ao consumo humano (WHO, 2011). Em comparação, segundo a Agência Americana de Proteção Ambiental
(EPA, do Inglês, Environmental Protection Agency), o valor máximo para este contaminante é de apenas 10,0 mg L-1 (USEPA, 1987). No Brasil, quando se trata de águas subterrâneas, há duas principais regulamentações que estabelecem diretrizes sobre a qualidade deste recurso, a Resolução CONAMA $n^{\circ} 396$ de 2008 (BRASIL, 2008) e a Portaria do Ministério da Saúde $n^{\circ}$ 2.914 de 2011 (BRASIL, 2011). Enquanto a primeira dispõe sobre a classificação e enquadramento das águas subterrâneas, a outra abrange procedimentos de controle e de vigilância da qualidade da água para consumo humano e seu padrão de potabilidade. Ambas estabelecem limites para certos parâmetros presentes na água. Assim, o $\mathrm{NO}_{3}$ - também é considerado padrão de potabilidade, sendo necessário seu controle em águas destinadas ao consumo. Tanto a Portaria do Ministério da Saúde $n^{\circ}$ 2.914 de 2011 quanto a Resolução CONAMA n 396 de 2008 delimitam a concentração deste parâmetro em 10,0 mg de $\mathrm{N} \mathrm{L}^{-1}$, expresso como $\mathrm{N}$.

Para estar apta ao consumo humano a água deve obedecer aos limites estabelecidos pelo Ministério da Saúde, descritos na Portaria № 2.914/2011, que padronizam parâmetros microbiológicos, físicos, químicos e radioativos atendendo a um padrão de potabilidade que não oferece riscos à saúde (MINISTÉRIO DA SAÚDE, 2011).

Dos sete ânions determinados neste trabalho, cinco estão enquadrados como parâmetros de potabilidade e por isso devem possuir concentrações abaixo dos níveis estipulados para caracterizar uma água como potável. Na Tabela 1, é possível observar o Valor Máximo Permitido (VMP) para cada elemento estudado nesta pesquisa.

Tabela 1 - VMPs estipulados para os ânions estudados

\begin{tabular}{cc}
\hline Ânions & VMP \\
\hline Nitrato $\left(\mathrm{NO}_{3}{ }^{-}\right)$ & $10,0 \mathrm{mg} \mathrm{de} \mathrm{N} \mathrm{L-1}$ \\
Nitrito $\left(\mathrm{NO}_{2}^{-}\right)$ & $1,0 \mathrm{mg} \mathrm{de} \mathrm{N} \mathrm{L-1}$ \\
Fluoreto $(\mathrm{F}-)$ & $1,5 \mathrm{mg} \mathrm{L}^{-1}$ \\
Cloreto $(\mathrm{Cl}-)$ & $250 \mathrm{mg} \mathrm{L}^{-1}$ \\
Sulfato $\left(\mathrm{SO}_{4}{ }^{2-}\right.$ & $250 \mathrm{mg} \mathrm{L}^{-1}$ \\
Fosfato $\left(\mathrm{PO}_{4}{ }^{-}\right)$ & - \\
Brometo $(\mathrm{Br}-)$ & - \\
\hline Fonte: Adaptado de MINISTÉRIO DA SAÚDE (2011).
\end{tabular}

\section{METODOLOGIA}

A pesquisa foi realizada no Município de Medianeira (PR), o qual possui 45.239 habitantes, em uma área com cerca de 328,7 $\mathrm{km}^{2}$ (IBGE, 2016). Medianeira está localizada no oeste do estado do Paraná onde faz divisa com os municípios de Matelândia, Missal, São Miguel do Iguaçu, Ramilândia, Itaipulândia e Serranópolis do Iguaçu.

O Município está localizado sob o divisor de águas de duas bacias hidrográficas pertencentes à bacia do Paraná III, a bacia do Rio Iguaçu e a sub-bacia do Rio Ocoí, situando-se sobre o Aquífero Serra Geral e este acima do Sistema Aquífero Guarani.
Para o levantamento das informações sobre qualidade da água foram monitorados 42 poços distribuídos pela área urbana e rural de Medianeira (PR), sendo que as coletas e monitoramentos ocorreram em duas etapas.

A seleção dos pontos levou em consideração as seguintes características: ocorrência de cadastro do poço junto ao órgão de controle ambiental estadual, homogeneidade na distribuição espacial, maior abrangência possível dentro do Município e densidade populacional das áreas. Desta forma, neste trabalho foram estudados 28 pontos situados na zona rural e 14 presentes na zona urbana. A Figura 1 apresenta um mapa com a localização dos poços de águas subterrâneos monitorados. 
Figura 1 - Localização e identificação dos poços monitorados e, no centro do mapa, a delimitação do perímetro urbano do município de Medianeira (PR)

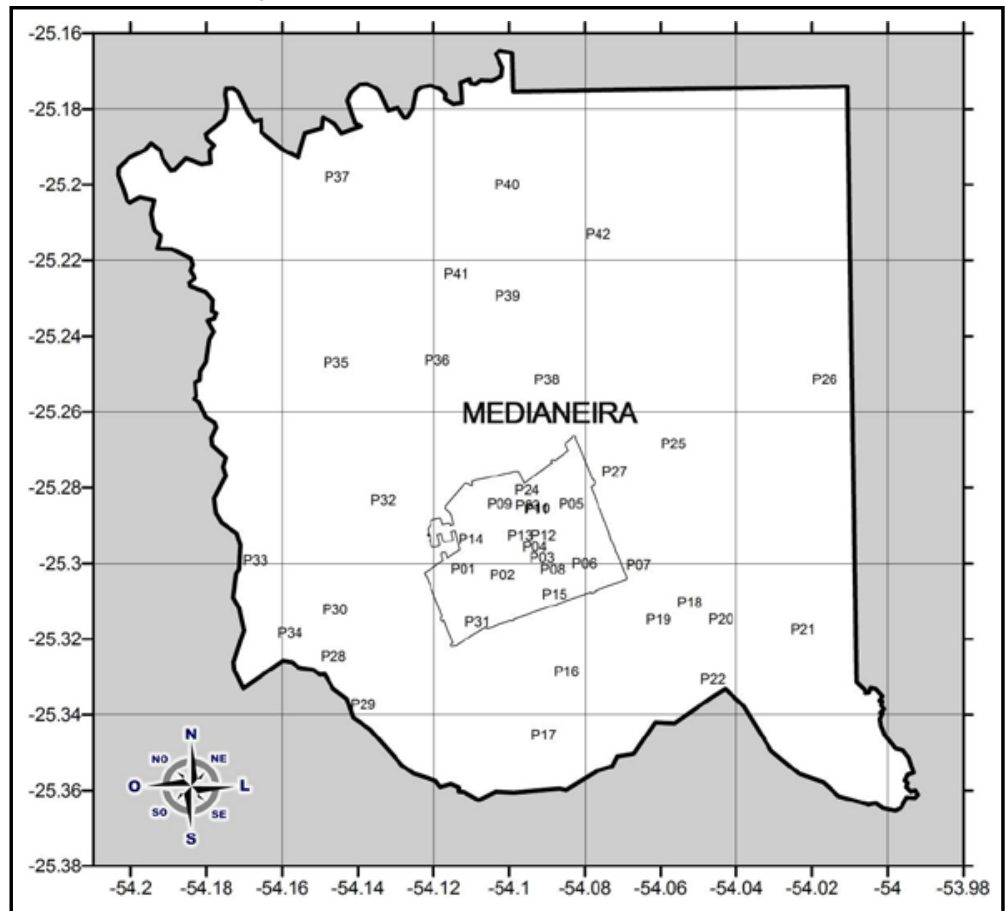

Fonte: Adaptado de IBGE (2015)

Para o inventário dos pontos de captação de água subterrânea, foi utilizada a base de dados disponibilizada pela Companhia de Pesquisa de Recursos Minerais (CPRM, 2016) por meio do Sistema de Informações de Águas Subterrâneas e a lista de Cadastro de Usuários de Recursos Hídricos disponibilizada pelo Instituto das Águas do Paraná - Águas Paraná.

A primeira etapa de coleta foi realizada em março de 2014, na estação definida como verão. Na região deste estudo, este período historicamente possui valores médios de 11 dias mensais com chuva, precipitação de $145 \mathrm{~mm}$ e temperatura de $24,2{ }^{\circ} \mathrm{C}$. A segunda campanha de coleta ocorreu durante a primavera, no mês de setembro, período que apresenta maiores níveis de precipitação, com média de $228 \mathrm{~mm}$, e temperaturas mais baixas, cerca de $22,3^{\circ} \mathrm{C}$ (EMBRAPA, 2015). O período de cada campanha de coleta durou aproximadamente 5 dias, sendo que estes dias foram caracterizados por céu com poucas nuvens, forte insolação e sem ocorrência de precipitação atmosférica.

As análises foram realizadas seguindo as recomendações do Standard Methods for the Examination of Water and Wastewater (APHA, 2012). Todas as coletas foram realizadas seguindo o mesmo procedimento para evitar contaminações e minimizar possíveis fontes de erro. Para tanto, as coletas das amostras foram realizadas diretamente no ponto mais próximo logo após a saída de água do poço, sendo que o ponto de coleta foi previamente limpo de sujidades mais grosseiras e posteriormente higienizado com álcool etílico $70^{\circ} \mathrm{GL}$. Logo em seguida, a saída de água foi mantida aberta com uma vazão constante por cerca de 5 minutos, de forma a não coletar a água que estava presente dentro das tubulações e também para retirar quaisquer resíduos presentes nas tubulações.
Foram utilizados frascos plásticos de polietileno de $500 \mathrm{~mL}$, previamente higienizados. Os frascos foram enxaguados seis vezes com água e armazenados, por 24 horas, com solução de $3 \%$ ( $\mathrm{v} / \mathrm{v})$ preparada a partir de detergente neutro Detertec ${ }^{\circledR}$, marca Sigma-Aldrich diluído em água ultrapura. Posteriormente, os frascos foram lavados mais seis vezes com água ultrapurificada.

Antes da coleta, os frascos para as análises físico-químicas foram enxaguados três vezes com a própria água a ser analisada. As amostras coletadas foram identificadas e armazenadas diretamente em caixa térmica refrigerada com gelo para manter as características do material até o laboratório, onde foram analisadas em até 48 horas.

Para as determinações dos ânions, foi utilizado um cromatógrafo de íons marca Thermo Scientific, modelo Dionex ICS-900 com detecção condutimétrica e câmara de supressão de regeneração química em modo DCR (do inglês, Displacement Chemical Regeneration), equipado com coluna de separação modelo AS23, marca Thermo Scientific.

Os resultados obtidos para os parâmetros determinados foram comparados com a Legislação vigente com relação aos padrões de potabilidade estabelecidos.

Para a elaboração de mapas e demais informações geográficas utilizou-se o SIG (Sistema de Informações Geográficas), por meio dos softwares Spring ${ }^{\circledR}$ versão 5.2.4, Surfer ${ }^{\circledR}$ versão 8 e Microsoft Excel ${ }^{\circledR}$ versão 2010. Com esses softwares, foram criados banco de dados, digitalização de dados vetoriais, inserção dos pontos, interpolação de dados, edição de polígonos, geração e cruzamento de mapas. 


\section{RESULTADOS E DISCUSSÃO}

\subsection{Primeira etapa}

Os resultados obtidos na primeira etapa de coleta e análises mostraram que as concentrações de $\mathrm{Cl}^{-}, \mathrm{SO}_{4}^{-}$e $\mathrm{NO}_{3}^{-}$em todas as amostras estavam dentro VMP recomendado pela Legislação.

A concentração de $\mathrm{NO}_{3}{ }^{-}$ficou acima do VMP nos pontos $\mathrm{P0} 5$ (11,0 mg de N L-1) e P10 (10,5 mg de N L-1), ambos situados na zona urbana. Os resultados revelaram que, para este elemento, a média nos pontos era de 2,9 $\mathrm{mg}$ de $\mathrm{N} \mathrm{L}^{-1}$, sendo encontrado em 41 pontos. Somente no local P37 não houve ocorrência deste ânion.

Quanto ao $\mathrm{F}$, o único ponto acima do permitido pela legislação foi o P37, com valores de 2,4 mg L-1, 13 vezes a média dos outros pontos. Assim como o $\mathrm{NO}_{3}$, este ânion esteve presente em $98 \%$ das amostras, mas em concentrações que não ultrapassavam $0,6 \mathrm{mg} \mathrm{L}^{-1}$.

Quanto ao $\mathrm{NO}_{2}$, houve ocorrência em apenas seis pontos, Ponto P4, P22, P35, P40, P33 e P23, sendo que nenhum local excedeu o limite estabelecido por Lei. A maior medição foi no P23,

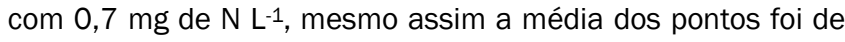
somente $0,05 \mathrm{mg}$ de $\mathrm{N} \mathrm{L}^{-1}$ para este analito.

$\mathrm{O} \mathrm{Cl}^{-}$foi o único ânion estudado que esteve presente em todas as amostras, apesar de possuir baixas concentrações quando comparado com o VMP, não excedendo em nenhum ponto o limite estipulado pela Legislação. A média foi $3,8 \mathrm{mg} \mathrm{L}^{-1}$, sendo que as quatro maiores concentrações encontradas (P05, P09, $\mathrm{P} 10$ e P11) estavam situadas em área urbana e muito próximas. Esses valores chegaram a ser de 3 até 10 vezes maiores do que a média dos pontos restantes.

Os resultados para $\mathrm{SO}_{4}{ }^{2-}$ nas amostras de águas foram bastante baixos, uma vez que o VMP para este íon é de $250 \mathrm{mg} \mathrm{L}^{-1}$ e que a média obtida foi de somente $1,4 \mathrm{mg} \mathrm{L}^{-1}$. 0 único ponto em que sulfato teve uma concentração mais elevada foi no poço P37, no qual se encontrou um valor de $14,7 \mathrm{mg} \mathrm{L}^{-1}$, mesmo assim não sendo suficiente para exceder os limites previstos na Legislação.

Para os íons de $\mathrm{Br}^{-}$e $\mathrm{PO}_{4}^{3-}$ não há VMP's estipulados e suas médias foram de $0,2 \mathrm{mg} \mathrm{L}^{-1} \mathrm{e}$ 0,6 $\mathrm{mg} \mathrm{L}^{-1}$ respectivamente. Estes íons estavam presentes em menos de um terço das amostras e apresentaram valores abaixo de 1,8 $\mathrm{mg} \mathrm{L}^{-1}$ para o $\mathrm{Br}^{-}$e 3,1 mg $\mathrm{L}^{-1}$ para o $\mathrm{PO}_{4}^{3-}$.

\subsection{Segunda Etapa}

Nesta segunda campanha, novamente as concentrações de $\mathrm{Cl}$, $\mathrm{SO}_{4}{ }^{2-}$ e $\mathrm{NO}_{2}$ - permaneceram abaixo dos limites estabelecidos pela Legislação em todas as amostras. Igualmente à primeira etapa, os ânions $\mathrm{F}^{-}$e $\mathrm{NO}_{3}$ - apresentaram alterações, desta vez mais pontos não atenderam ao padrão de potabilidade. Apenas um ponto apresentou concentração elevada para F- e 04 deles exibiram valores acima do VMP para $\mathrm{NO}_{3}$.
Nesta segunda etapa, o $\mathrm{NO}_{3}$ - foi o parâmetro que mais apresentou valores acima do recomendado, sendo isso registrado em 04 poços. A média desta espécie química foi da ordem de 3,2 $\mathrm{mg}$ de $\mathrm{N} \mathrm{L}^{-1}$, demonstrando leve aumento em relação à concentração média da primeira etapa. Em 03 destes pontos (P11, P12 e $\mathrm{P} 13$ ) os valores para $\mathrm{NO}_{3}$ atingiram concentrações pouco acima do máximo permitido, sendo que no poço $\mathrm{P} 42$, a concentração foi de 13,7 mg de $\mathrm{N} \mathrm{L}^{-1}$.

O ânion F- esteve presente na maioria das amostras, mas só foi detectada concentração acima do VMP recomendado em apenas 01 ponto, com reincidência no ponto P37, onde a concentração foi de $2,2 \mathrm{mg} \mathrm{L}^{-1}$.

Dos 05 pontos onde houve ocorrência de $\mathrm{NO}_{2}$ na primeira etapa, nenhum ponto teve o VMP ultrapassado. Todos os pontos estavam situados na zona urbana e não foi detectada a presença deste ânion na primeira etapa. No ponto P05, local com maior concentração deste ânion, o valor foi de 0,5 mg de $\mathrm{N} \mathrm{L}^{-1}$.

A concentração de $\mathrm{SO}_{4}{ }^{2-}$ foi mais elevada no local P37, com concentração de $14,8 \mathrm{mg} \mathrm{L}^{-1}$, valor próximo ao da primeira etapa. Entretanto, em nenhum local foram constatadas concentrações deste ânion acima do VMP.

Novamente, o $\mathrm{Cl}^{-}$esteve presente em todas as amostras, mas com baixas concentrações, média de 4,4 mg L-1. Das 07 maiores concentrações observadas 06 estavam em poços situados na área urbana, reafirmando a ocorrência na primeira etapa. 0 único local da área rural foi o poço $\mathrm{P} 42$, que também apresentou elevação da concentração de $\mathrm{NO}_{3}{ }^{-}$e $\mathrm{SO}_{4}{ }^{2-}$ quando comparado com valores encontrados na primeira etapa.

Para $\mathrm{Br}^{-}$e $\mathrm{PO}_{4}^{3-}$ as médias foram de $0,1 \mathrm{mg} \mathrm{L}^{-1}$ e $1,2 \mathrm{mg} \mathrm{L}^{-1}$ respectivamente. Durante a segunda etapa os valores para $\mathrm{PO}_{4}{ }^{3-}$ apresentaram aumento significativo indo de 1,1 para $12,8 \mathrm{mg}$ $\mathrm{L}^{-1}$ no ponto $\mathrm{P} 17$ e de 3,12 para $12,4 \mathrm{mg} \mathrm{L}^{-1}$ no ponto $\mathrm{P} 23$, quando comparados com a primeira análise.

Na Tabela 2 pode-se observar uma variação significativa entre valores mínimos e máximos determinados para todos os analitos, resultando em uma amplitude elevada. Com base nestes resultados, pode-se constatar que os valores acima do VMP ocorrem de maneira bastante pontual nos poços monitorados. Valores baixos destes ânions e valores acima do VMP ocorrem em poços próximos uns dos outros.

Na Figura 2 estão mostrados os valores médios dos resultados dos ânions analisados nas duas etapas. Devido ao grande número de amostras com baixos teores, a média dos pontos está abaixo do VMP, mesmo que em alguns casos fosse possível observar o não cumprimento da Legislação.

As maiores variações entre os pontos foram detectadas para os ânions nitrato e cloreto. Apesar do $\mathrm{Cl}^{-}$apresentar maior amplitude, o VMP para este parâmetro é bastante alto, não representando risco o consumo desta água. Entretanto, para o $\mathrm{NO}_{3}$, em dois pontos a média das coletas ultrapassou esse limite, indicando risco o consumo humano. 
Tabela 2 - Análise estatística dos aníons em todos os pontos estudados

\begin{tabular}{|c|c|c|c|c|c|}
\hline Ânion & Mínimo* & Máximo* & Intervalo* & $\dot{x}^{*}$ & $\sigma^{*}$ \\
\hline Nitrato $\left(\mathrm{NO}_{3}{ }^{-}\right)$ & 0,00 & 10,18 & 10,18 & 3,05 & 3,00 \\
\hline Nitrito $\left(\mathrm{NO}_{2}^{-}\right)$ & 0,00 & 0,36 & 0,36 & 0,05 & 0,09 \\
\hline Fluoreto (F-) & 0,02 & 2,33 & 2,31 & 0,25 & 0,35 \\
\hline Cloreto (Cl-) & 1,18 & 22,23 & 21,06 & 4,12 & 4,26 \\
\hline Sulfato $\left(\mathrm{SO}_{4}{ }^{2-}\right)$ & 0,00 & 14,73 & 14,73 & 1,50 & 2,18 \\
\hline Fosfato $\left(\mathrm{PO}_{4}^{3-}\right)$ & 0,00 & 1,72 & 1,72 & 0,18 & 0,38 \\
\hline Brometo (Br-) & 0,00 & 6,97 & 6,97 & 0,91 & 1,51 \\
\hline
\end{tabular}

Figura 2 - Comparação entre concentração média dos pontos separados por área rural e urbana do Município de Medianeira-PR

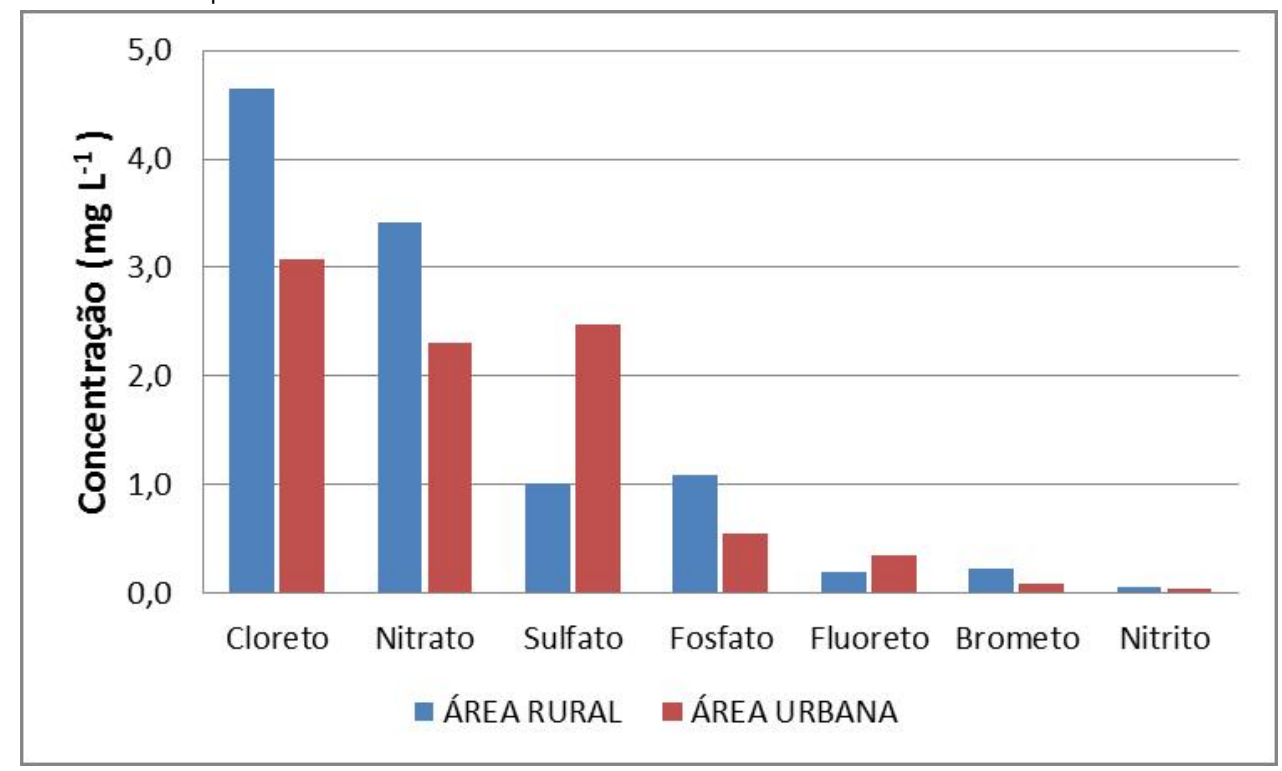

Utilizando como referência a média das duas coletas, estes parâmetros foram inseridos em mapas georeferenciados para serem visualizados quanto sua distribuição espacial. Estas representações nos permitem determinar em quais locais da área de estudo estas espécies químicas foram encontradas com valores acima do VMP. Estes mapas estão representados na Figura 3, onde os locais com concentrações acima do VMP estão delimitados pela linha tracejada. 
Figura 3 - Mapas da área de estudo com as concentrações médias dos ânions $\mathrm{NO}_{3}$ e e F-

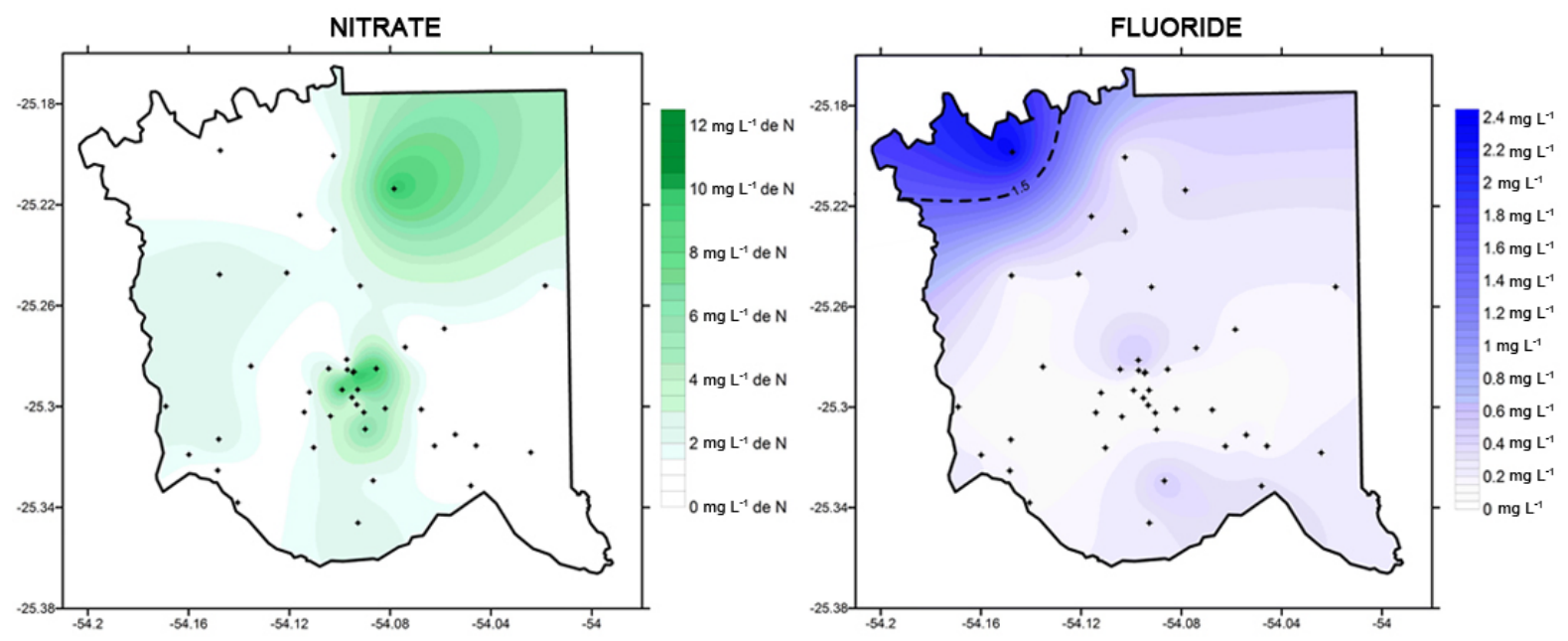

Avaliando-se as condições das águas dos poços concluiu-se que em muitos pontos não são aceitáveis de acordo com as normas exigidas para consumo humano, necessitando-se de medidas de tratamento preliminar da água para posterior consumo.

A Portaria do Ministério da Saúde n 2.914 de 2011 define água potável como toda aquela que atenda aos padrões estabelecidos e ao mesmo tempo não ofereça riscos à saúde, uma vez que outros parâmetros não listados podem causar danos à saúde. Neste sentido, 05 dos 07 ânions estudados são considerados parâmetros indicadores de potabilidade nas águas consumidas.

Para os 07 ânions avaliados, apenas o $\mathrm{NO}_{3}^{-}$e $\mathrm{F}^{-}$apresentaram concentrações acima do VMP durante as duas etapas. Para $\mathrm{Cl}$, $\mathrm{SO}_{4}{ }^{2-}$ e $\mathrm{NO}_{3}$ - foram verificados valores dentro da Legislação para todos os pontos. Para $\mathrm{PO}_{4}{ }^{3-}$ e $\mathrm{Br}$ a ocorrência foi pequena e com valores baixos, entretanto estes parâmetros não são considerados padrão de potabilidade, não possuindo VMP estabelecido.

\section{CONCLUSÕES}

Os resultados revelaram que é necessária mais atenção quanto à exploração e proteção da água subterrânea no município estudado, uma vez que em muitos locais a qualidade é inadequada para o consumo humano. Além disso, essa situação pode se agravar pelo impacto e presença cada vez maior da atividade antrópica.

Assim, mesmo as alterações de concentração que foram visualizadas apenas no período de um ano devem ser acompanhadas. $O$ atendimento dos padrões estabelecidos pelas normas que asseguram a potabilidade da água não pode ser somente assegurado em dado momento. Assim, os resultados obtidos neste monitoramento revelam a importância do monitoramento contínuo dos recursos hídricos subterrâneos.

\section{AGRADECIMENTOS}

Os autores agradecem aos responsáveis pelos poços escolhidos como pontos de coleta, pelo auxílio no repasse das informações necessárias a este estudo, à UTFPR - Câmpus Medianeira, e à CAPES pela bolsa de mestrado concedida.

\section{REFERÊNCIAS}

ÁGUAS PARANÁ. Instituto das Águas do Paraná. Poços outorgados no município de Medianeira. [mensagem pessoal]. Mensagem recebida por <mariokondo@águasparana.pr.gov.br> em 14 ago. 2013.

APHA. Standard Methods for the examination of water and wastewater. 22 ed. Washington: APHA, 2012.

BRASIL. Conselho Nacional do Meio Ambiente. Resolução CONAMA $n^{\circ}$ 396, de 3 de abril de 2008. Diário Oficial da União. 7 abr. 2008.

BRASIL. Ministério da Saúde. Portaria do Ministério da Saúde $n^{\circ}$ 2.914, de 12 de dezembro de 2011. Diário Oficial da União, 14 dez. 2011.

BRENDER J.D. et al. Prenatal nitrate intake from drinking water and selected birth defects in offspring of participants in the National Birth Defects Prevention Study. Environmental Health Perspectives, v. 121, n. 9, 2013.

CPRM. Sistema de Informações de Águas Subterrâneas. Poços no município de Medianeira. Disponível em <http://siagasweb.cprm.gov.br/layout/visualizar_mapa.php>Acesso em: 08 set. 2016.

EMBRAPA. Médias históricas em estações do IAPAR. Disponivel em: $<$ http://www.iapar.br/modules/conteudo/conteudo.php?conteudo=1070 >. Acesso em: 29 jan. 2015.

FERNICOLA, N. G. G.; AZEVEDO, F. A. Metemoglobinemia e nitrato nas águas. Revista Saúde Pública, v. 15, n. 2, 1981.

IBGE. Cidades@ - Paraná - Medianeira. Disponivel em <http://cidades.ibge.gov.br/xtras/perfil.php?lang $=\&$ codmun $=411580 \&$ search $=$ parana|Medianeira| infograficos:-informacoes-completas> Acesso em: 10 mar. 2016.

IBGE. Mapa do município de Medianeira/PR - 2010. Disponível em <

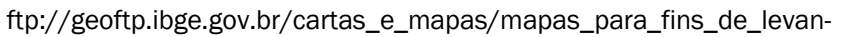
tamentos_estatisticos/censo_demografico_2010/mapas_municipais_estatisticos/pr/medianeira_v2.pdf> Acesso em: 10 mar. 2015. 
KNOBELOCH L. et al. Blue babies and nitrate contaminated well water. Environmental Health Perspectives, v. 108, n. 7, 2000.

MACILWAIN C. US report raises fears over nitrate levels in water. Nature, v. 377, n. 4, 1995.

MEINERZ, C.C. et al. Geração de resíduos provenientes da suinocultura na região Oeste do Paraná: Um caso de insustentabilidade. Scientia Agraria Paranaensis, v. 10, n. 2, 2011.

RICO-GARCíA, E et al. Nitrate content on summer lettuce production using fish culture water. Trends in Agricultural Economics, v. 2, n. 1, 2009.

ROSA FILHO, E.F.; et al. As Águas subterrâneas do Estado do Paraná. Curitiba: Maxi Gráfica, 2010.
SILVA, L. P.; MIRANDA, J. H.; OLIVEIRA, L. A.; JOSE, J. V. Effect of companion ion on nitrate displacement through transport parameters analysis. Engenharia Agrícola, v. 35, n. 1, 2015.

TUCCI, C. E. M.; CABRAL, J. J. S. P. Prospecção tecnológica, recursos hí dricos: qualidade da água. Brasília, DF: CGEE, 2003. Disponível em: <http://www.cgee.org.br/arquivos/a2b_agua_sub.pdf>. Acesso em: 08 mar. 2017.

USEPA. Estimated national occurrence and exposure to nitrate and nitrite in public drinking water supplies. Washington: United States Environmental Protection Agency, Office of Drinking Water, 1987.

WHO. Nitrate and Nitrite in Drinking water. WHO/SDE/WSH/ 07.01/16/Rev/1. Geneva: World Health Organization, 2011. 